\title{
REDESIGN DE ABRIDOR DE LATAS E GARRAFAS SOB O VIÉS ERGONÔMICO
}

\section{AN ERGONOMIC APPROACH TO REDESIGN A TIN AND BOTTLE OPENER}

\author{
Marina Tomiatti ${ }^{1}$, Bach. \\ Mirela de Giuli², Bach. \\ Erica Tobaro ${ }^{3}$, Bach. \\ Emilene Zitkus ${ }^{4}$, D. Sc.
}

\author{
(1) Universidade Estadual Paulista - UNESP - Bauru \\ e-mail: marina.tomiatti@gmail.com \\ (2) Universidade Estadual Paulista - UNESP - Bauru \\ e-mail: mirela_rgiuli@outlook.com \\ (3) Universidade Estadual Paulista - UNESP - Bauru \\ e-mail: erica.tobaro@gmail.com \\ (4) Universidade Estadual Paulista - UNESP - Bauru \\ e-mail: emilenezitkus@gmail.com
}

Palavras-chave em português (ergonomia, usabilidade, Design)

Este artigo apresenta a metodologia utilizada para o desenvolvimento do projeto e produção de um protótipo de abridor de latas e garrafas. Este projeto foi concebido com base em resultados de testes de usabilidade que avaliavam ergonomia, conforto e estética dos abridores comuns.

\section{Key-words in English (Ergonomics, Usability, Product design)}

This article presents the methodology used for the development of the design and production of a prototype of can opener and bottles. This project was based on results of usability tests that evaluated the ergonomics, comfort and aesthetics of common openers.

\section{Introdução}

Os abridores de lata são um utensílio indispensável em qualquer cozinha, mas seus modelos mais populares não costumam variar de formato e material, sendo geralmente pequenos, finos, com a lâmina de perfuração curva, pouco elaborados e feitos em metal. A pouca variação entre modelos força o usuário a utilizar um produto que não lhe oferece uma boa experiência de uso, o que pode gerar "muitos constrangimentos aos usuários, que pode variar de uma simples insatisfação até o desconforto percebido, ou mesmo a ocorrência de patologias graves nas extremidades dos membros superiores" [PASCHOARELLI, 2010, 2].
Isso é causado porque, na maioria das vezes, $o$ produto não é pensado em sua totalidade, como dimensões, peso, textura, estabilidade, forma de uso, etc. De acordo com Campos (2014), pensar o produto considerando a totalidade de suas características perceptivas pode contribuir para o design ergonômico deste produto, criando condições de uso nas quais a tecnologia esteja adequada à capacidade dos usuários.

Entretanto, como se trata de um produto com um formato estabelecido, qualquer modificação ergonômica, funcional e estética deve ser bem pensada para não criar um conflito entre o modelo mental que o usuário tem daquele objeto e a novo modelo de interação que está sendo apresentado, porque isso também afetaria dinâmica entre $o$ 


\section{Ergodesign \& HCI}

número especial, volume 5 , ano 5 (2017) ISNN 2317-8876, Rio de Janeiro - Brasil
PUC-Rio Pontifícia Universidade Católica do Rio de Janeiro Departamento de Artes \& Design | PPGDesign

LEUI | Laboratório de Ergodesign e Usabilidade de Interfaces produto e o usuário. Esse modelo é fundamental porque é através dele que o usuário irá explicar a operação do sistema [NORMAN, 2006]. Esta relação entre o usuário e o sistema é um dos focos de pesquisa e aplicação de um projeto de produto, sendo que um de seus principais segmentos é o design ergonômico, cujo princípio é a aplicação do conhecimento ergonômico no projeto de dispositivos tecnológicos, com o objetivo de alcançar produtos e sistemas seguros, confortáveis, eficientes, efetivos e aceitáveis. [PASCHOARELLI, 2003]. E além do design ergonômico, a Usabilidade apresenta-se como um novo parâmetro para a compreensão dessa relação entre o usuário e sistema [PASCHOARELLI e CAMPOS, 2013]. Ao entender a importância da interação do usuário com o produto, o designer deve buscar métodos para coletar as informações necessárias para nortear o projeto e dessa forma, incorporar ao produto as reais necessidades e desejos dos consumidores. Uma possibilidade é através da Ergonomia Participativa, descrito por Itiro Iida (2005) como o método pelo qual os usuários finais do produto desempenham um papel ativo na identificação e na análise dos problemas ergonômicos, assim como na formulação e implementação de suas soluções. No caso do redesenho do abridor de latas, que é um produto já existente, o desenvolvimento aconteceria através do Projeto Participativo, no qual o usuário é envolvido desde a etapa inicial. Desde o início o projeto é focalizado no usuário e na tarefa. Dessa forma, os usuários fazem avaliações contínuas a cada etapa do projeto. Assim, os eventuais erros ou desvios do projeto são corrigidos antes de se chegar ao protótipo [IIDA, 2005].

Tão importante quanto compreender essa interação, é ter em mente que outros aspectos também são cruciais para o desenvolvimento de um instrumento manual. Dentre eles se destaca a antropometria, mais especificamente a antropometria da mão humana. Apesar de ter grande importância, ainda é uma área pouco estudada no Brasil, mas os primeiros estudos já mostram que existem significativas diferenças entre gêneros, a tal ponto de serem relevantes para o dimensionamento deste tipo de instrumento manual [PASCHOARELLI, 2010]. Apesar da importância, o que ainda vemos é a manutenção de projetos que remetem a períodos onde não existia a preocupação com o conforto do usuário, com a anatomia da mão ou com a prevenção de doenças repetitivas, como é o caso desse modelo de abridor, que é largamente utilizado no país. Conveniente citar que esse modelo de abridor não é comercializado em muitos outros lugares, pois foi substituído por modelos com partes giratórias ou, até mesmo, modelos elétricos. Talvez a preferência seja por esse modelo fino com a lâmina lateral por conta de seu baixo custo, o que facilita a troca em caso de enferrujamento e desgaste da lâmina.

Portanto, o trabalho desenvolvido envolveu a remodelagem total do objeto, alterando o tamanho, o volume, o peso, o material, e o tipo de pega e, para isso, considerou a anatomia masculina e feminina. Mas, por ser um produto universal, houve grande dificuldade em estabelecer as medidas que fossem adequadas e fossem confortáveis para o maior número de pessoas possível, uma vez que existem diferenças significativas entre as mãos masculinas e femininas, e estas precisam ser consideradas.

O presente artigo apresenta o resultado do trabalho interdisciplinar proposto pelos docentes do curso de Design de produto da UNESP, que teve como objetivo redesenhar e produzir um protótipo de abridor de latas e garrafas que utilizasse diretrizes de ergonomia. O protótipo passou por dois tipos de testes de usabilidade, que é considerado um dos melhores métodos para se avaliar, com precisão, o desempenho dos produtos [LEWIS, 2006]. E, para que fosse possível registrar as melhorias alcançadas com o protótipo, o abridor de lata comum também passou pelos mesmos testes. Esses primeiros testes, além de serem usados para comparação, também auxiliaram a identificação dos maiores problemas do produto, o que serviu e guia durante o desenvolvimento do projeto. Ao final, a análise e comparação dos resultados dos testes demonstrou que houve considerável melhora na interação do usuário com o produto, e sua percepção de conforto e segurança.

\section{Procedimentos metodológicos}

Os procedimentos metodológicos realizados no decorrer do desenvolvimento do protótipo se dividiram em: aplicação de testes de ergonomia e usabilidade com um abridor comum; pesquisa de similares; diretrizes iniciais de projeto; desenvolvimento de projeto e; produção do protótipo. 


\section{Ergodesign \& HCI}

número especial, volume 5 , ano 5 (2017) ISNN 2317-8876, Rio de Janeiro - Brasil
PUC-Rio Pontifícia Universidade Católica do Rio de Janeiro Departamento de Artes \& Design | PPGDesign

LEUI | Laboratório de Ergodesign e Usabilidade de Interfaces

\subsection{Aplicação de testes de ergonomia e usabilidade ao abridor comum}

Os testes foram aplicados em abridores de latas comuns, e se basearam em duas metodologias diferentes, sendo a primeira uma lista com dez assertivas acerca da experiência de uso que o usuário deveria marcar se concordava totalmente, concordava parcialmente, não concordava nem discordava, discordava parcialmente e discordava totalmente com essas afirmações. Este tipo de teste é chamado de SUS (System Usability Scale), e cada posição de concordância ou discordância recebe uma pontuação de 1 a 5 , sendo 10 "discordo totalmente" e o 5 o "concordo totalmente". O cálculo da pontuação também muda de acordo com o tipo de pergunta, se for uma afirmação positiva sobre o produto, o cálculo deve ser feito com a fórmula "posição-1", logo, se o usuário concordar totalmente com a assertiva (posição que vale 5), então essa resposta dará 4 pontos ao produto, que é o máximo que uma questão positiva pode valer. Se a assertiva for negativa, a fórmula se altera para " 5 posição", então, se o usuário discordar totalmente da afirmação (posição que vale 1), essa resposta também dará 4 pontos ao produto.

Por exemplo, se o produto testado for excelente e o usuário concordar com todas as afirmativas positivas e discordar de todas as afirmativas negativas, a soma dos resultados dará 40. Mas para obter a pontuação geral do SUS, esse valor deve ser multiplicado por 2,5. No exemplo dado, a pontuação geral seria $40 * 2,5=100$.

O segundo teste é o DS (Diferencial Semântico). Nele, são colocados dez pares de adjetivos antagônicos, e o usuário deve indicar, numa escala de dez pontos, a qual dos adjetivos aquele produto mais se aproxima. A pontuação corre de 1 a 10, e o resultado final é a soma de todas as médias de todas os pares de adjetivos. Cada um dos adjetivos recebe uma classificação entre positivo e negativo, e elas devem ser escolhidas antes da aplicação do teste. Para ilustrar, neste teste o par caro/barato, tem como elemento positivo o "barato" e negativo o "caro", e o objetivo do teste é que o produto seja percebido com maior número de características positivas possível, pois assim sua pontuação final irá aumentar.
Por exemplo, se um dos pares de adjetivos é "higiênico - anti-higiênico", sendo que o caráter positivo é o de higiênico, e o negativo é o de antihigiênico, e a percepção do usuário é de que aquele produto é muito higiênico, então a pontuação para esse par será com números altos. Ao final de todos os sujeitos testarem, é feita uma média com os valores atribuídos a cada par. E, ao final, todas as médias para os dez pares são somadas para chegar ao número final.

Como pode ser visto na figura 1 , os testes aplicados ao abridor comum tiveram médias de 63 pontos (SUS) e 49,70 pontos (DS). Essas médias colocam esse abridor em uma posição mediana de desempenho, não sendo excelente nem totalmente ruim. Pelo teste SUS, baseado nas perguntas, esse abridor teve pior desempenho nas questões que envolviam a facilidade da pega e a qualidade do material utilizado no produto. O resultado do teste DS mostrou que o abridor foi percebido pelos usuários como anti-higiênico, geométrico, barato, intuitivo, repulsivo, sério, anti-ergonômico, minimalista, poluente, excludente, rústico e indesejável.

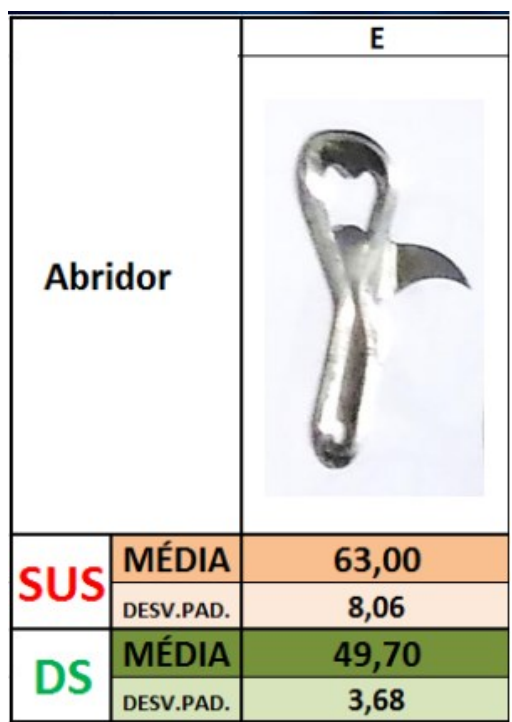

Figura 1- Resultados dos testes aplicados ao abridor comum. Fonte: Elaborado pelas autoras 2016.

Esses resultados nortearam o desenvolvimento do protótipo para o abridor, pois a equipe soube quais eram as deficiências deste tipo de produto e, assim, pode conceber um novo design que pudesse melhorar o desempenho geral do abridor, tanto no caráter estético quanto no ergonômico e funcional. 


\subsection{Pesquisa de similares}

A etapa de pesquisa de similares teve como objetivo conhecer melhor os modelos de abridores disponíveis no mercado para, assim, ser possível listar suas principais características, como tamanho, formato, material e preços de comercialização. A equipe buscou imagens que fugissem do formato convencional de um abridor de latas e de garrafas, mas é difícil encontrar produtos que sejam muito diferentes do modelo que foi usado nos testes de usabilidade aplicados em sala de aula. De qualquer modo, de cada abridor encontrado foi possível extrair características que pudessem auxiliar a criação de algo novo, ergonômico e com melhorias estéticas. Alguns desses itens podem ser vistos nas figuras 2 e 3 .

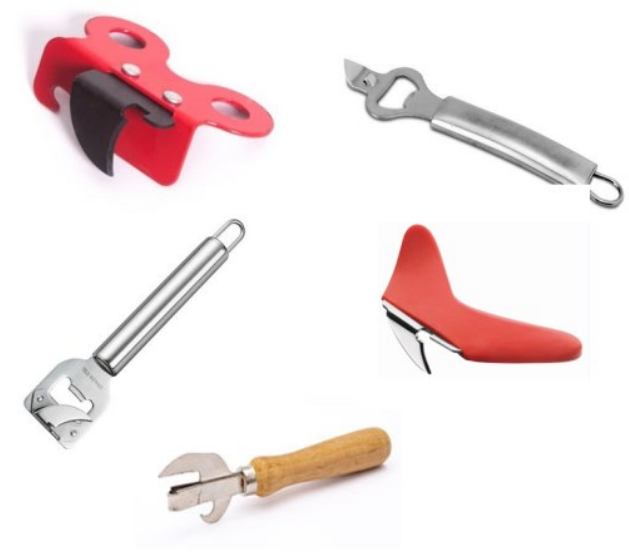

Figura 2 - Similares do abridor de latas. Fonte: Elaborado pelas autoras, 2017.

Esses abridores são modelos diferentes dos abridores comuns, principalmente pelas pegas em forma de cabo, e pelos materiais utilizados, que são de madeira ou borracha, ou até mesmo de metal colorido.

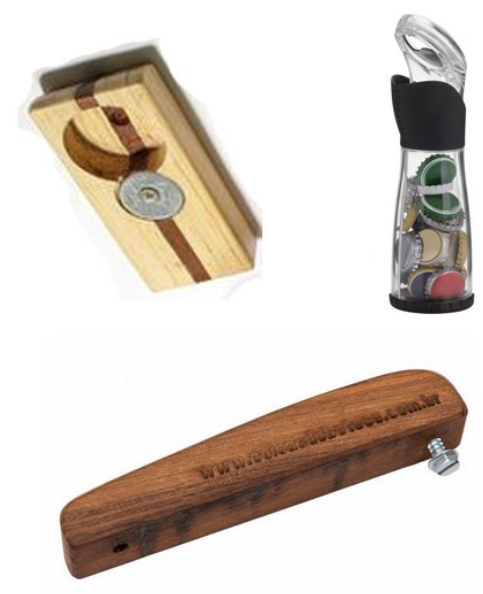

Figura 3 - Similares do abridor de garrafas. Fonte: Elaborado pelas autoras, 2017.

O abridor de garrafas, embora não tenha sido testado, foi uma parte importante para o desenvolvimento do protótipo, uma vez que ele seria útil para equilibrar o formato do produto. Assim, foi feita a busca por modelos que fossem muito diferentes dos tradicionais. Através dessa pesquisa, viu-se a necessidade de criar um meio de segurar a tampa da garrafa, de modo a evitar que esta caísse quando fosse aberta.

\subsection{Diretrizes iniciais de projeto}

As conversas iniciais para o desenvolvimento do projeto foram pautadas na experiência pessoal que cada membro da equipe teve com o produto, em conversas com usuários que trabalhavam em bares e restaurantes, e nos resultados dos testes DS e SUS que foram feitos com o abridor de latas comum. Sendo assim, ficou claro que o tipo de pega e a área de contato entre a mão do usuário e o corpo do produto precisavam ser alterados para melhorar a experiência de uso, de modo a facilitar o movimento que se faz ao abrir a lata e preservar os músculos da mão. Além disso, uma das diretrizes iniciais era fazer um produto que fosse tanto para destros quanto para canhotos, mas não foi possível atingir esse objetivo pela dificuldade em manipular o metal da lamina.

O resultado do teste de usabilidade mostrou com clareza quais melhoras precisavam ser feitas no abridor comum, e isso determinou as seguintes diretrizes de projeto:

Conforto ao usuário; 


\section{Ergodesign \& HCI}

número especial, volume 5 , ano 5 (2017) ISNN 2317-8876, Rio de Janeiro - Brasil
PUC-Rio Pontifícia Universidade Católica do Rio de Janeiro Departamento de Artes \& Design | PPGDesign

LEUI | Laboratório de Ergodesign e Usabilidade de Interfaces
- $\quad$ Produto com maior área de contato com a mão do usuário;

- $\quad$ Alteração da pega para diminuir o stress muscular;

- Modificação do sistema de abertura de garrafas;

- Utilização da madeira para a construção do corpo do produto.

\subsection{Desenvolvimento de projeto}

Após alguns desenhos, a equipe achou que seria mais interessante elaborar alguns modelos para que algumas das soluções fossem testadas antes de serm aplicadas no protótipo final, assim, haveria chance de alterar o projeto sem que os resultados prejudicassem o desempenho do produto durante os testes.

O primeiro modelo foi feito em madeira de eucalipto, pois havia a necessidade de testar o peso, a textura e o tamanho limite das bordas do produto para que não houvesse interferência durante a abertura da lata (figura 4). Neste modelo, foi instalada a lâmina que seria usada no protótipo final, e foi testado o apoio para a lata com o parafuso, mas isso se mostrou ineficaz durante a abertura.

Esse modelo mostrou que a lâmina e o corpo do produto não poderiam ficar no mesmo plano, pois o corpo bateria na lata, impedindo sua abertura.

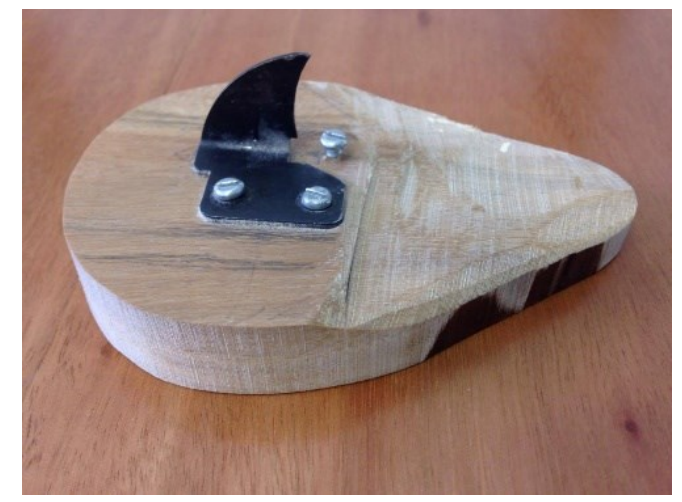

Figura 4- Primeiro modelo testado Fonte: Fotografado pelas autoras, 2016.
O segundo modelo foi feito em poliuretano (PU) e modelado no laboratório. O objetivo era testar o tamanho do produto e sentir se ficava confortável na mão (figura 5). Além disso, também foram adicionadas áreas que facilitariam o encaixe dos dedos, mas, após o teste, a conclusão foi de que seria melhor se houvesse um rebaixo apenas para o encaixe dos polegares.

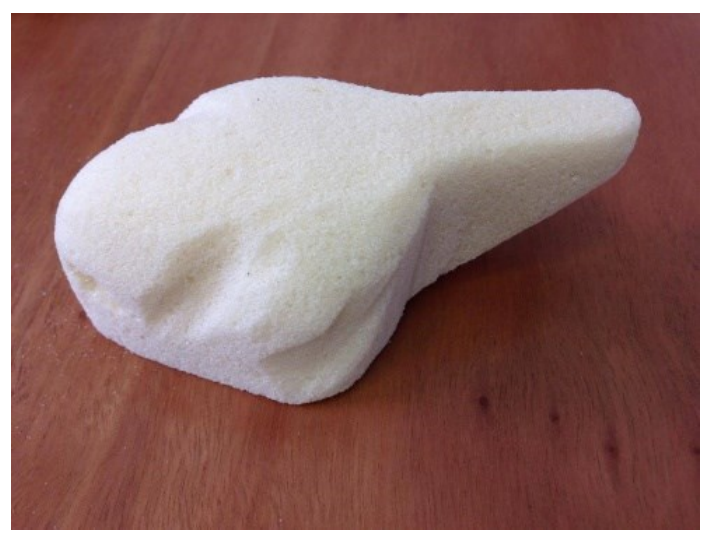

Figura 5 - Segundo modelo testado Fonte: Fotografado pelas autoras, 2016.

O terceiro modelo testado foi feito em madeira, e o objetivo era testar o tipo de pega para o abridor (figura 6). Com esse modelo simples, que tinha a lâmina do abridor em um plano diferente do corpo do mesmo, foi possível testar a pega com as mãos fechadas (como se fosse um joystick), e o pega superior (como se fosse um mouse). O stress causado durante o movimento de alavanca mostrou que a pega superior não seria tão adequada para este produto, e que o mesmo movimento, mas com o punho fechado, seria menos desgastante para o usuário.

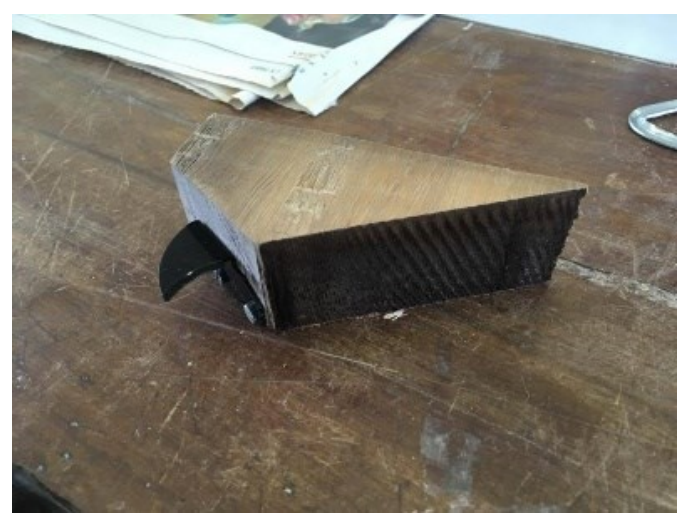

Figura 6- Terceiro modelo testado Fonte: Fotografado pelas autoras, 2016. 


\section{Ergodesign \& HCI}

número especial, volume 5 , ano 5 (2017) ISNN 2317-8876, Rio de Janeiro - Brasil
PUC-Rio Pontifícia Universidade Católica do Rio de Janeiro Departamento de Artes \& Design | PPGDesign

LEUI | Laboratório de Ergodesign e Usabilidade de Interfaces
O quarto modelo testado envolveu a instalação de duas lâminas (figura 7). Esse teste foi feito para verificar se era possível desenvolver um protótipo para destros e canhotos, o que tornaria o produto mais adequado para um número maior de pessoas, entretanto, apenas instalar a lâmina não melhoraria a experiência de um canhoto porque o apoio de ferro que encaixa na borda da lata ficaria ao contrário, o que impediria a abertura da lata.

Como não seria viável remodelar a estrutura da lâmina, essa ideia de que o produto fosse ambidestro foi descartada.

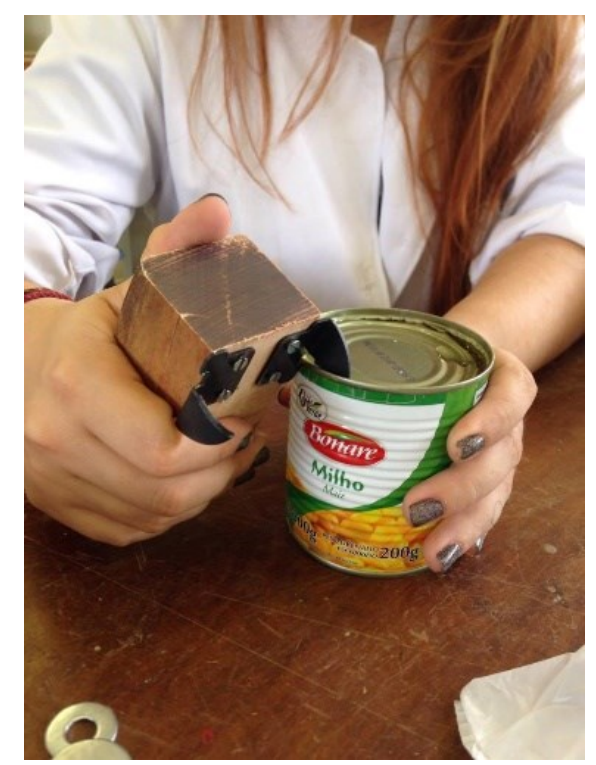

Figura 7- Quarto modelo testado Fonte: Fotografado pelas autoras, 2017.

Apesar dos resultados esclarecedores, a equipe ainda não havia definido o formato final do produto, pois houve certa dificuldade em encontrar um desenho que unisse a ergonomia, a funcionalidade e a beleza. Mas, foi apenas durante uma discussão sobre a memória que cada uma tinha sobre produtos de pega confortável, que surgiu a ideia de usar o cabo da plaina manual como inspiração para o design (figura 8).

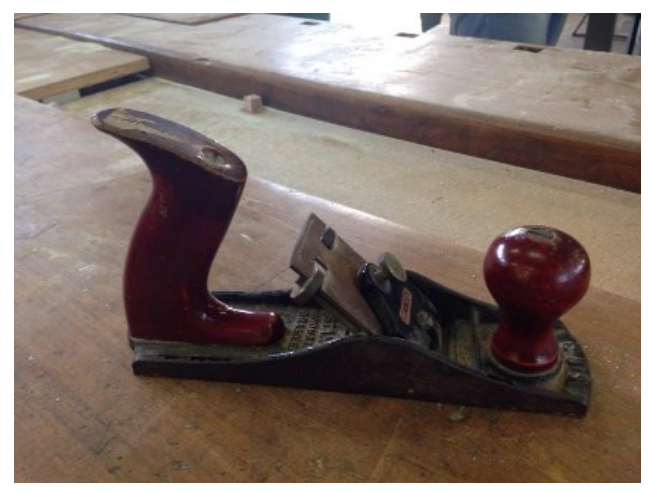

Figura 82- Referência para o formato do abridor Fonte: Fotografado pelas autoras, 2017.

A plaina foi usada por dois membros da equipe durante o desenvolvimento de um outro projeto, e o conforto e segurança que esse cabo ofereceram durante o uso da ferramenta foram notáveis, e foi essa experiência de uso que a equipe buscava para o produto, então concordamos em investir nessas curvas paralelas que culminam em planos quase equivalentes.

\subsection{Produção do protótipo}

A produção do protótipo foi feita no Laboratório Didático de Materiais e Protótipos da FAAC- Bauru, e fez uso de toda a infraestrutura do lugar, tanto no que diz respeito aos materiais quanto às ferramentas necessárias para a produção.

A produção começou com a seleção da madeira que seria usada para a confecção do corpo do abridor. $\mathrm{O}$ intuito do projeto, apesar de ter mais ênfase na ergonomia do produto, também era de utilizar o mínimo possível de matéria-prima, e de preferência que esta fosse o resíduo de algum outro projeto. Por ser um protótipo pequeno, foi fácil encontrar madeira disponível no laboratório que, inclusive, já se encontrava desengrossada e desempenada. Foi utilizada a madeira de eucalipto porque é bonita, resistente, e traria um ar de rusticidade e bom acabamento ao produto.

Como a peça desengrossada estava menor do que a largura do protótipo, foi necessário cortar o bloco em quatro partes, e depois colar essas partes com cola branca. Assim, a largura do protótipo ficou correta e foi possível iniciar o processamento.

Depois da secagem da cola, cortamos as pontas do bloco em $45^{\circ}$, como pode ser visto na figura 9 . 


\section{Ergodesign \& HCI}

número especial, volume 5 , ano 5 (2017)

ISNN 2317-8876, Rio de Janeiro - Brasil
PUC-Rio Pontifícia Universidade Católica do Rio de Janeiro Departamento de Artes \& Design | PPGDesign

LEUI | Laboratório de Ergodesign e Usabilidade de Interfaces

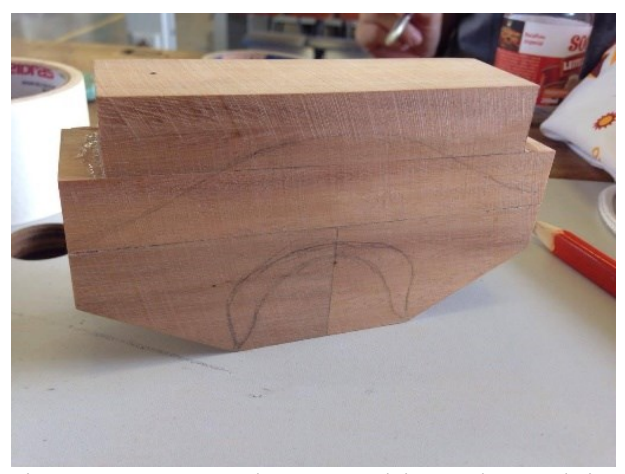

Figura 93- Corte de $45^{\circ}$ no bloco de madeira Fonte: Fotografado pelas autoras, 2017.

Com essa parte finalizada, os furos para o abridor de garrafas foram feitos. Utilizamos duas brocas chatas, uma de 3 / 4 e a outra de $11 / 8$, para os furos da arruela e da tampa da garrafa, respectivamente (figura 10). A vantagem de fazer esse furo com a broca chata é que a ponta dela já criava o furo que seria colocado o imã.

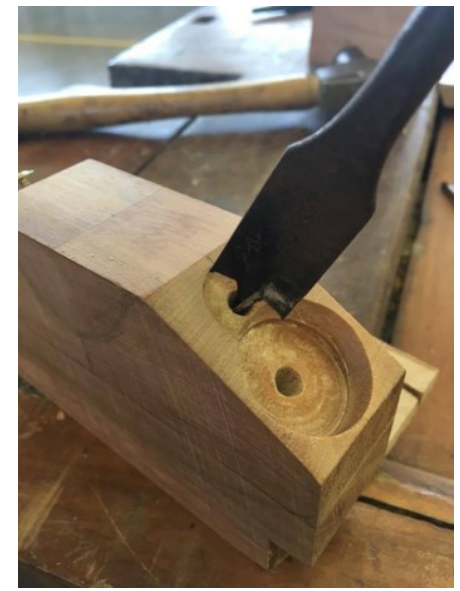

Figura 10- Furos com a broca chata Fonte: Fotografado pelas autoras, 2017.

Após a furação foi preciso lixar a parte interna para deixa-la uniforme, pois a broca deixou saliências que poderiam atrapalhar o encaixe das tampas (figura 11).

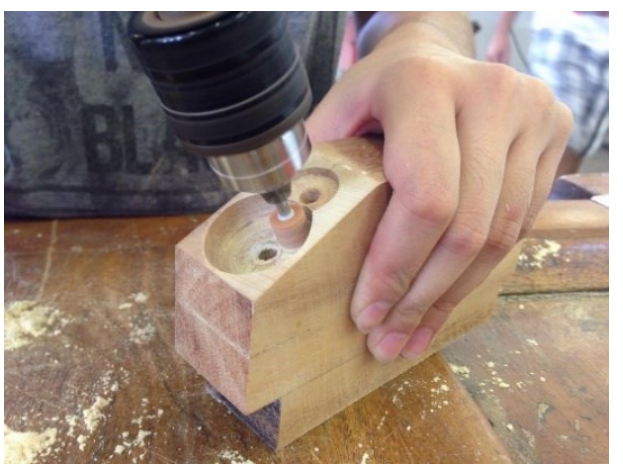

Figura 11- Lixamento da parte interna dos furos Fonte: Fotografado pelas autoras, 2017.

Depois disso, os furos para os parafusos que seguram a lâmina foram feitos com a furadeira (figura 12).

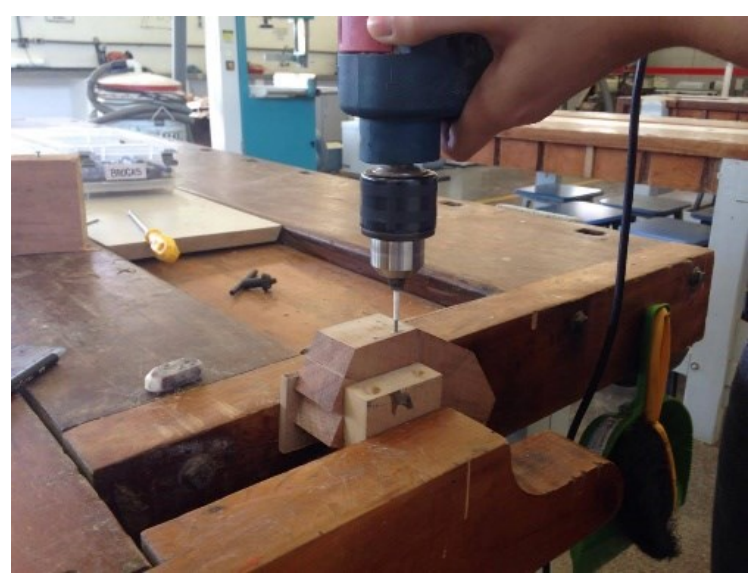

Figura 124- Furação para a lâmina do abridor Fonte: Fotografado pelas autoras, 2017.

Neste momento foi iniciada a modelagem do formato do abridor. Primeiro foi traçado o perfil de corte (figura 13), depois essa parte foi eliminada com a serra de fita (figura 14). Em seguida, a peça foi lixada na lixadeira circular (figura 15) que retirou as pontas e uniformizou as curvas.

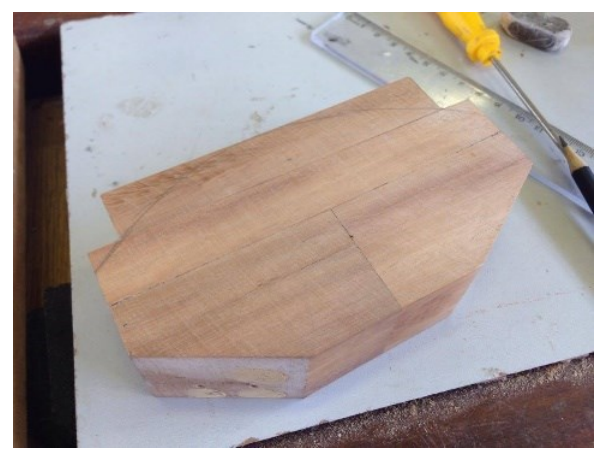

Figura 135 - Marcação do corte Fonte: Fotografado pelas autoras, 2017. 


\section{Ergodesign \& HCI}

número especial, volume 5 , ano 5 (2017) ISNN 2317-8876, Rio de Janeiro - Brasil
PUC-Rio Pontifícia Universidade Católica do Rio de Janeiro Departamento de Artes \& Design | PPGDesign

LEUI | Laboratório de Ergodesign e Usabilidade de Interfaces

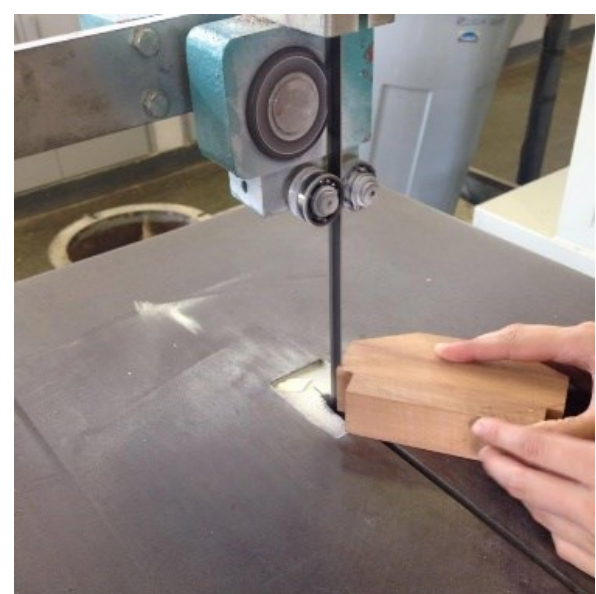

Figura 14- Corte na serra de fita Fonte: Fotografado pelas autoras, 2017.

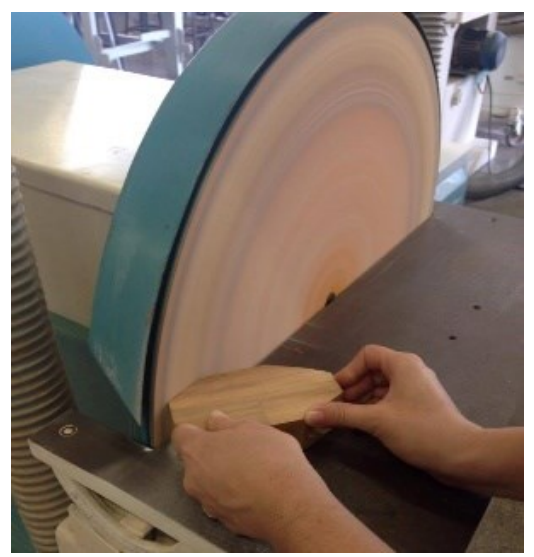

Figura 15- Lixando as quinas na lixadeira circular Fonte: Fotografado pelas autoras, 2017.

Neste momento, com menos material na peça, foi feito o desenho de como seria o perfil final do abridor (figura 16). Esse perfil foi desenhado com base no formato do cabo da plaina, e o desenho foi disposto de forma que utilizasse os furos que já haviam sido feitos.

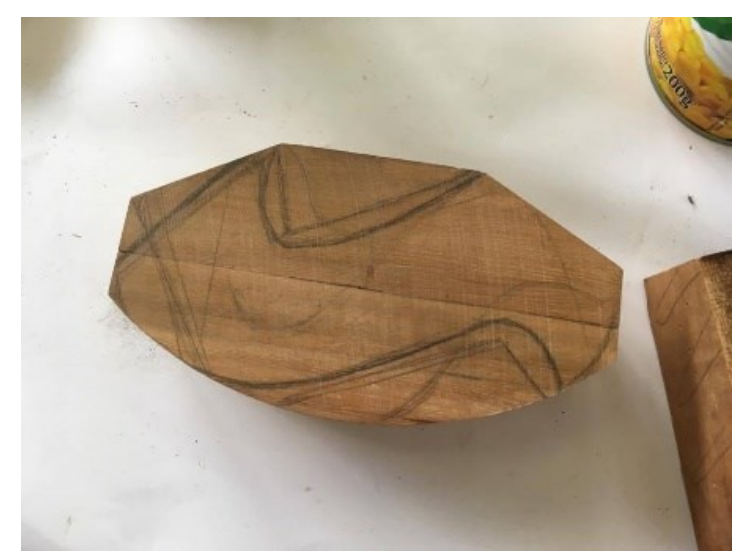

Figura 16- desenho do perfil do abridor Fonte: Fotografado pelas autoras, 2017.

O corte foi feito na serra de fita e, como é um equipamento que não faz curvas com perfeição, foi preciso deixar uma certa distância do desenho, o que acabou gerando áreas pontiagudas. Para eliminar e uniformizar tais áreas, foi necessário usar a lixadeira circular nas superfícies externas da peça, e a grosa e a retífica nas curvas que estavam na parte interna e que, por isso, a lixadeira não conseguia alcançar (figura 17).

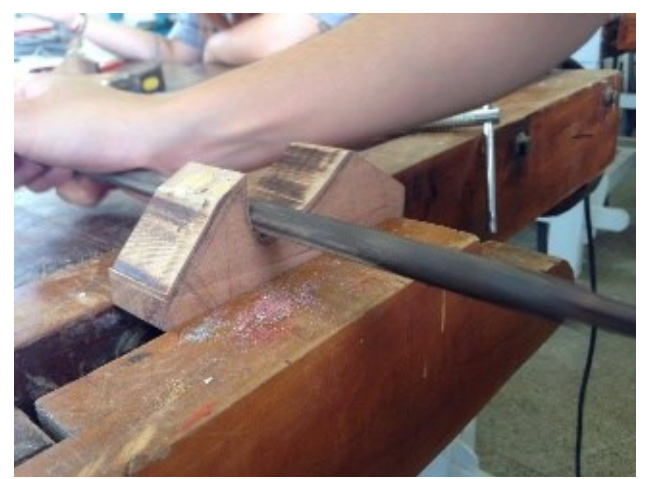

Figura 17- Desbaste da superfície interna com a grosa Fonte: Fotografado pelas autoras, 2017.

Após a definição do perfil do protótipo, restava arredondar as arestas, de forma que o objeto se tornasse macio ao toque. Para isso, foi utilizada a retífica, que é uma ferramenta mais precisa ao lixar pequenas áreas (figura 18). O objetivo era arredondar as arestas de forma uniforme, mas como o trabalho foi puramente manual, não foi possível conferir se os raios eram exatamente os descritos no projeto executivo.

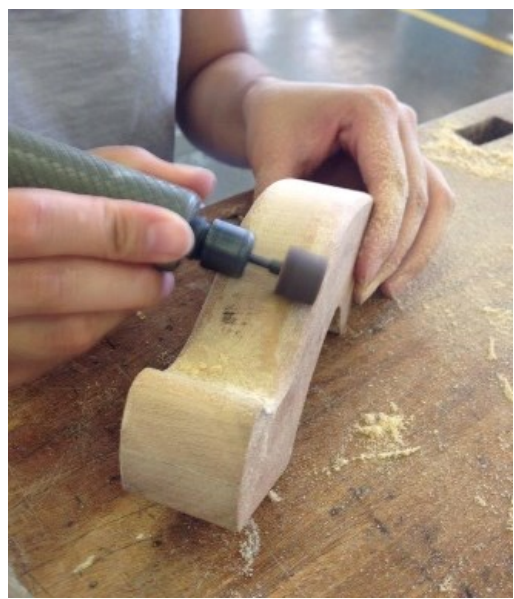

Figura 18- Arredondamentos das arestas feito com a retífica 


\section{Ergodesign \& HCI}

número especial, volume 5 , ano 5 (2017)

ISNN 2317-8876, Rio de Janeiro - Brasil

Fonte: Fotografado pelas autoras, 2017.

Após o uso da retífica, foi feito uso da folha de lixa grão 150 para eliminar possíveis arranhões que as lixas anteriores, que eram todas grão 80 , pudessem ter deixado na peça (figura 19).

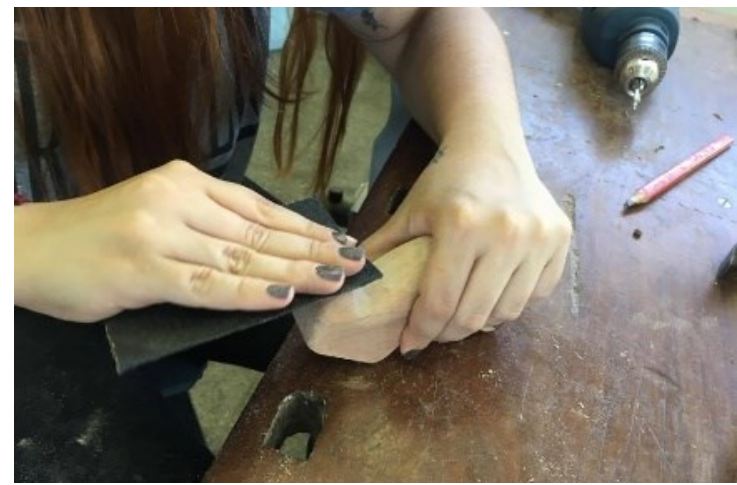

Figura 19- Lixamento da peça com lixa 150 Fonte: Fotografado pelas autoras, 2017.

A montagem foi feita depois que a peça principal estava envernizada, e foi preciso instalar a lâmina, o imã e a arruela. A lâmina, por ser de um produto comercializado, precisou ser desencaixada de seu produto original. Para isso, foi preciso limar os rebites que prendiam a lâmina ao corpo do abridor (figura 20).

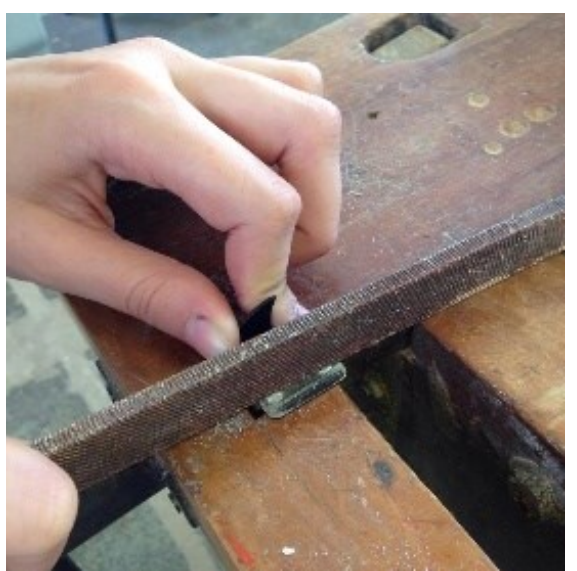

Figura 206- Desbaste dos rebites para liberar os dois furos da lâmina

Fonte: Fotografado pelas autoras, 2017

O projeto previa que todos os componentes fossem pretos, então foi preciso pintar todos os componentes com tinta spray preta. Feito isso, foi preciso apenas parafusar a lâmina ao corpo de madeira e a arruela (figura 21), e o imã foi colado com cola quente.
PUC-Rio Pontifícia Universidade Católica do Rio de Janeiro Departamento de Artes \& Design | PPGDesign

LEUI | Laboratório de Ergodesign e Usabilidade de Interfaces
Figura 21- Arruela sendo parafusada
Fonte: Fotografado pelas autoras, 2017.

O corpo do protótipo estava pronto, e recebeu a aplicação de duas camadas de verniz Sparlack duplo filtro solar brilhante natural. Entre a primeira e a segunda demão de verniz foi feito um lixamento com lixa d'água grão 400. Abaixo estão as fotos do produto finalizado.
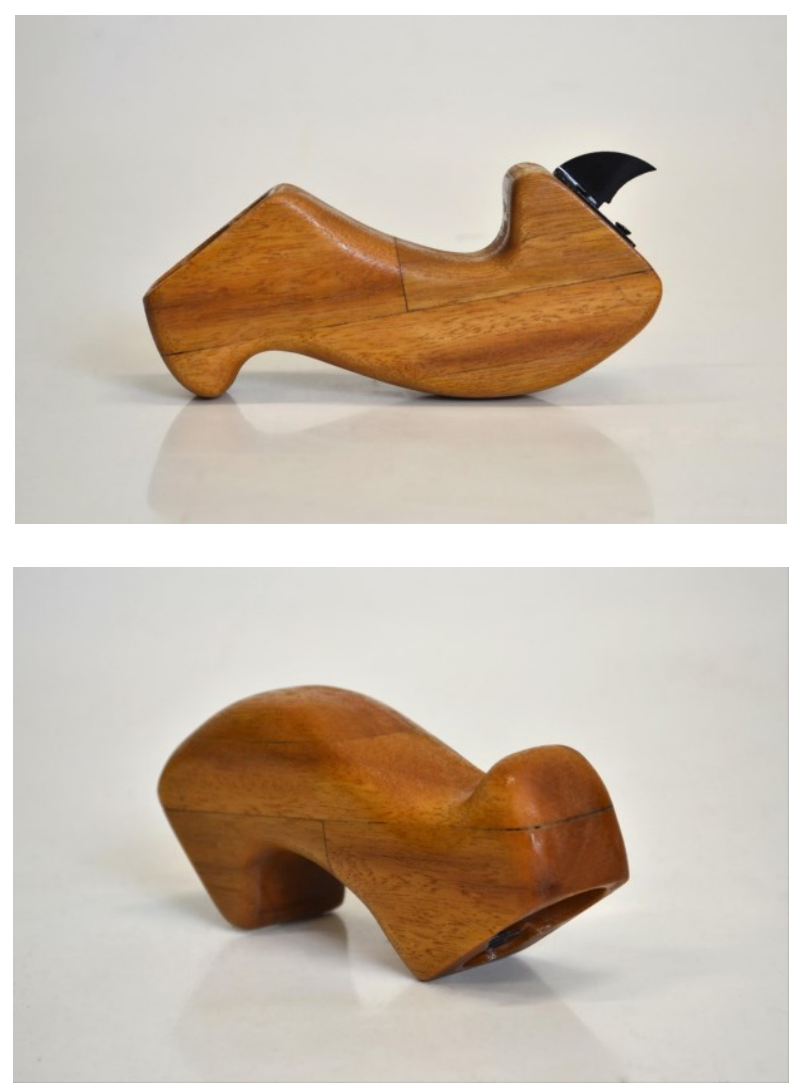


\section{Ergodesign \& HCI}

número especial, volume 5 , ano 5 (2017) ISNN 2317-8876, Rio de Janeiro - Brasil

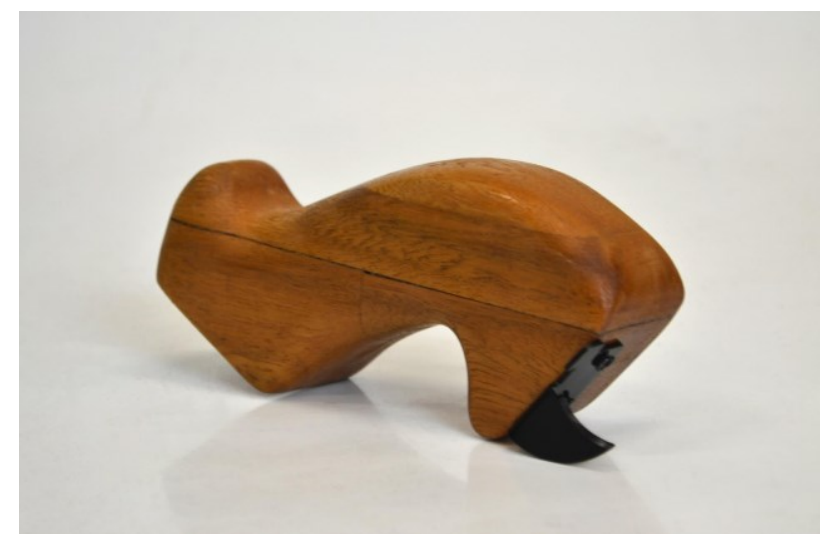

Figura 22 - Protótipo final do abridor. Fonte: Fotografias feitas pelas autoras, 2017

\section{Resultados e discussões}

Com o protótipo físico acabado, foi realizada a aplicação dos testes de ergonomia e usabilidade com o novo modelo a fim de recolher dados para comparação com o teste previamente realizado e, assim, quantificar e qualificar a melhora alcançada com o redesenho do produto.

\subsection{Aplicação de testes de ergonomia e usabilidade com o protótipo}

A aplicação dos testes de ergonomia e usabilidade com o protótipo também foram realizadas com o acompanhamento dos docentes tendo como usuários os alunos membros das outras equipes (Figura 23). As equipes foram dispostas no ambiente da sala de aula de forma que em cada mesa houvesse um protótipo, a lata a ser aberta e pelo menos um membro da equipe que o desenvolveu. Os docentes desenvolveram uma tabela que continha o um número de identificação para cada aluno, a ordem da rodada de teste e para qual mesa o aluno deveria se deslocar ao final de cada rodada. O objetivo era que dessa forma cada aluno testasse pelo menos três dos protótipos desenvolvidos pelas equipes e que cada protótipo avaliado por 9 alunos, sendo que os membros da equipe não testaram o próprio protótipo para o levantamento de dados dessa atividade. As etapas de teste foram divididas em: atividade de abertura de uma lata de milho com tempo cronometrado e o posterior preenchimento dos questionários SUS e DS.
PUC-Rio Pontifícia Universidade Católica do Rio de Janeiro Departamento de Artes \& Design | PPGDesign

LEUI | Laboratório de Ergodesign e Usabilidade de Interfaces

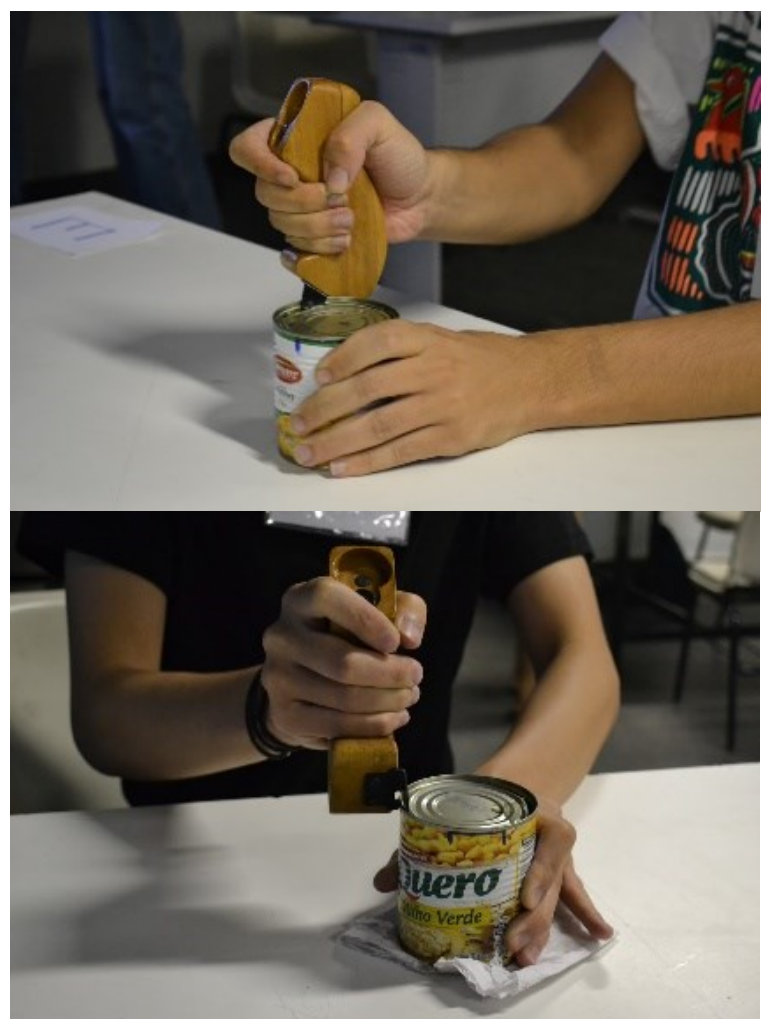

Figura 23 - Teste de usabilidade do protótipo. Fonte: Imagem gerada pelas autoras, 2017.

\subsection{Análise dos resultados}

Os testes de usabilidade geraram resultados numéricos importantes, mas não se limitou a isso. $\mathrm{O}$ contato do usuário com o objeto gera dois tipos de resposta, a primeira que é tátil e a segunda visual [CAMPOS, 2014]. Ambas as interações não são mensuráveis, mas influenciam, positiva ou negativamente, a percepção do usuário sobre aquele objeto. Assim, ainda que os testes não perguntem diretamente sobre detalhes da experiência, muitos dos usuários explicitaram opiniões sobre $\mathrm{o}$ protótipo, tanto por seu formato, quanto pelo material e pelo peso. Então, além do resultado científico claro, também foi possível descobrir detalhes acerca da experiência pessoal de cada um.

De maneira geral, tanto o teste DS quanto o SUS obtiveram resultados superiores aos do abridor comum. A melhora, em ambos os casos, foi de 11\% em comparação com os resultados obtidos no primeiro teste, o que é muito positivo para a avaliação geral do protótipo, porque, mesmo sendo o primeiro protótipo, foi possível melhorar a percepção geral do produto e seu desempenho frente aos usuários. 


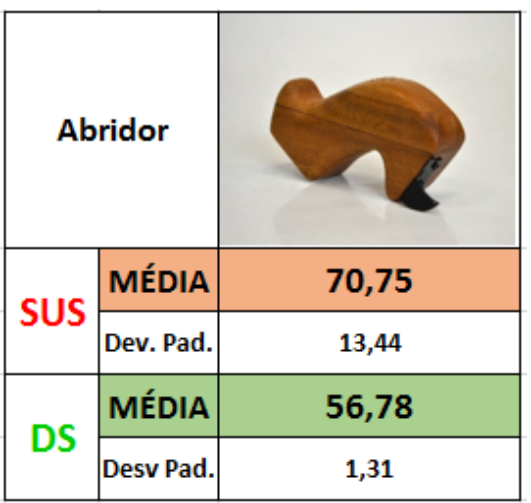

Figura 24 - Resultados dos testes de usabilidade

Fonte: Elaborado pelas autoras, 2017.

Especificamente, a análise do resultado do SUS mostra que das dez questões, seis obtiveram melhores pontuações quando comparadas ao teste com o abridor comum, como pode ser visto no gráfico abaixo.

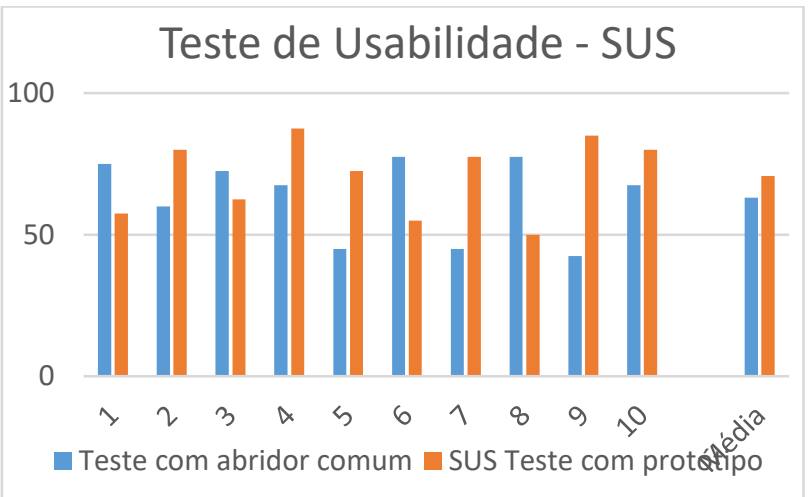

Gráfico 1- Teste de usabilidade SUS

Fonte: Elaborado pelas autoras, 2017.

Essas quatro questões, que eram a de número 1, 3, 6 e 8, tratavam sobre o design formal do produto, sua manipulação, seu formato e sua facilidade de uso. A equipe previa que esse aspecto não seria tão bem avaliado, visto que o corpo do abridor e sua pega foram completamente modificados e em nada se assemelha ao abridor comum. Assim, já era de se esperar que houvesse certa dificuldade ao entender o modo de uso do produto. Apesar disso, é fato que esse ponto precisa ser melhorado para que os usuários compreendam a forma de manipulação intuitivamente, e não tenham dúvidas quanto a maneira de utilizar o abridor.

O teste DS apresentou melhorias também. Dos doze pares, sete tiveram aumento na pontuação e alteração do adjetivo mais próximo da experiência de uso. Neste teste, o protótipo foi percebido como higiênico, anatômico, atraente, ergonômico, sustentável, elaborado e desejável. Todos esses adjetivos foram considerados positivos para esse teste, e se opuseram aos adjetivos escolhidos para o abridor comum, que eram todos negativos.

A figura 25 compara os resultados dos testes com os dois abridores, e demonstra que houve uma melhora significativa na percepção do objeto. Entretando, dois adjetivos negativos se mantiveram nos dois produtos, que foram "sério" e "excludente". Outros três pares, que antes eram avaliados com características positivas, no protótipo foram avaliados com características negativas, que são "caro", "complicado" e "exagerado".

\begin{tabular}{|c|c|c|c|c|}
\hline \multicolumn{5}{|c|}{$\overline{D S}$} \\
\hline Negativo/Positivo & \multicolumn{2}{|c|}{ Teste com abridor comum } & \multicolumn{2}{|c|}{ Teste com protótipo } \\
\hline ANTI-HIGIÊNICO/HIGIÊNICO & 4,8 & Anti-higiênico & 5,8 & Higiênico \\
\hline GEOMÉTRICO/ANATÔMICO & 4,0 & Geométrico & 5,2 & Anatômico \\
\hline CARO/BARATO & 6,5 & Barato & 2,6 & Caro \\
\hline COMPLICADO/INTUITIVO & 5,2 & Intuitivo & 4,1 & Complicado \\
\hline REPULSIVO/ATRAENTE & 3,9 & Repulsivo & 6,1 & Atraente \\
\hline SÉRIO/DIVERTIDO & 2,6 & Sério & 3,1 & Sério \\
\hline ANTI-ERGONÔMICO/ERGONÔMICO & 4,0 & Anti-ergonômico & 5,8 & Ergonômico \\
\hline EXAGERADO/MINIMALISTA & 5,2 & Minimalista & 3,4 & Exagerado \\
\hline POLUENTE/SUSTENTÁVEL. & 3,8 & Poluente & 5,9 & Sustentável \\
\hline EXCLUDENTE/INCLUSIVO & 2,7 & Excludente & 3,6 & Excludente \\
\hline RÚSTICO/ELABORADO & 3,1 & Rústico & 5,0 & Elaborado \\
\hline $\begin{array}{l}\text { INDESEJÁVEL/DESEJÁVEL } \\
\text { MÉDIA }\end{array}$ & 3,9 & $\begin{array}{l}\text { Indesejável } \\
49,70\end{array}$ & 6,2 & $\begin{array}{l}\text { Desejável } \\
56,78\end{array}$ \\
\hline $\begin{array}{l}\text { * Prevalência do par negativo. } \\
\text { " Prevalência do par positivo } \\
\text { " Prevalência do par negativo se }\end{array}$ & & & & \\
\hline
\end{tabular}

Figura 25 - Comparativo entre os resultados do teste DS Fonte: Elaborado pelas autoras, 2017.

Esses resultados servirão de base para a elaboração e refinamento deste protótipo, mas nem todos precisam, necessariamente, de atenção. É o caso de "caro", "sério" e "exagerado", que não são necessariamente ruins para a descrição de um produto, pois essa percepção é variável de acordo com o público alvo a ser atingido e a intenção comercial de quem produz. Assim, tais adjetivos não seriam determinantes para um próximo protótipo.

Os únicos adjetivos que serão considerados em uma posterior revisão de projeto serão o "excludente" e o "complicado", visto que eles influenciam na facilidade de acesso e uso do produto, e se opõe às diretrizes inicialmente estabelecidas para o projeto. Desta forma, é preciso ainda alcançar a forma que sirva para usuários destros e canhotos, e que se apresente de maneira mais intuitiva e simples, pois a 
insegurança e encaixe da mão durante o uso pode provocar acidentes.

\subsection{Revisão do projeto com base na avaliação dos usuários}

O resultado do teste de usabilidade mostrou que a forma de manusear o produto foi o ponto com mais avaliações negativas, então esse seria o principal ponto a ser repensado no design do abridor. A usabilidade busca a máxima funcionalidade de um produto [PASCHOARELLI, 2003], então a dificuldade de compreensão percebida quanto ao modo de uso é um fator que deve ser revisada e modificado, sob pena do produto não se adequar a proposta de ser ergonomicamente viável. Além disso, como diz Seva (2011, apud CAMPOS, 2014) as propriedades estéticas do objeto também influenciam em sua usabilidade aparente, podendo atrair ou não o usuário, o que influencia no momento da opção pela compra ou não daquele produto. Desta maneira, a percepção do consumidor é muito importante para o projeto, uma vez que isso pode determinar o sucesso ou fracasso na aceitação e disseminação daquele objeto.

Em posterior análise, percebe-se que o produto não é tão intuitivo em sua forma de uso, principalmente porque seu formato não remete a nenhuma característica do modelo convencional, o que confunde o usuário, uma vez que ele, automaticamente, tenta reproduzir o modo de uso ao qual ele está acostumado. Portanto, como o formato em si do objeto não causou desconforto, acreditamos que uma solução possível para esse problema de intuitividade seria a construção de um suporte que induzisse o usuário a pegar o objeto na posição correta. Assim, além de elucidar a forma de uso, o suporte também serviria para expor o objeto como parte da decoração da cozinha ou churrasqueira. As ideias iniciais sugerem que o suporte seja preso a uma parede, e o produto seja encaixado a ele, com a lâmina voltada para o chão.

Também consideramos como opção a colocação de uma proteção para a lâmina, de modo que ela não fique exposta, já que ela, por si só, é uma saliência grande no produto. Assim, não haveria o risco de cortes e machucados durante o armazenamento, caso este fosse feito em uma gaveta cheia de outros utensílios de cozinha.
Outro aspecto que precisa ser repensado é o fato do produto atender apenas a destros e não possibilitar a utilização segura por pessoas canhotas. Esse é um problema encontrado também nos modelos antigos, então o redesign deveria se preocupar em atender ambos os perfis de usuário. Nesse primeiro protótipo não foi possível pensar em mecanismos que mudassem a lâmina de posição por limitações técnicas de laboratório, mas esse aspecto não pode ser esquecido para o refinamento do modelo.

\section{Conclusão}

Por fim, os resultados dos testes indicam que o protótipo final atendeu às diretrizes do projeto. $\mathrm{O}$ produto proposto obteve bons resultados relacionados tanto à sua estética quanto aos requisitos ergonômicos. A aplicação de testes de usabilidade aumentou a compreensão das reais necessidades dos usuários e das formas de interação com interfaces, permitindo a tomada de decisões mais assertivas durante o desenvolvimento do produto. Uma das limitações dos testes foi ter envolvido apenas jovens adultos, não refletindo as dificuldades de outros grupos, como idosos e pessoas com dificuldades motoras. Para que este protótipo possa pensar em ser comercializado, é preciso incluir novos grupos de usuários, variando idade e capacidade motora, a fim de conseguir mapear com maior precisão as fraquezas do produto.

\section{Bibliografia}

ASSOCIAÇÃO BRASILEIRA DE NORMAS TÉCNICAS. NBR 10098: Folha de desenho leiaute e dimensões. Rio de Janeiro: 1987.

NBR 10582: Apresentação da folha para desenho técnico. Rio de Janeiro: 1988.

\section{CAMPOS, L. F. A. Usabilidade, percepção} estética e força de preensão manual: influência no design ergonômico de instrumentos manuais: um estudo com tesouras de poda. 2014. 289 p. Tese (doutorado) - UNESP, 2014.

IIDA, ITIRO. Ergonomia: projeto e produção. / Itiro Iida - $2^{\mathrm{a}}$ edição ver. E ampl. - São Paulo: Editora Blucher, 2005. 
LEWIS, J.R. Usability testing. In: SALVENDY, G. (Ed.). Handbook of Human Factors and Ergonomics. New York: John Wiley, p. 1275-1316, 2006.

MEDOLA, F. O., PASCHOARELLI, L. C.

Resultados Teste de Usabilidade 1. Bauru, 2016. NORMAN, DONALD A. O design do dia-a-dia./ Donald A. Norman; tradução Ana Deiró. - Rio de Janeiro: Rocco, 2006.

PASCHOARELLI, L. C. Usabilidade aplicada ao design ergonômico de transdutores de ultrassonografia: uma proposta metodológica para avaliação e análise do produto. 2003. 142 p. Tese (Doutorado) - UFSCar, São Carlos, 2003.

PASCHOARELLI, L. C.; CAMPOS, L. F. A. Usabilidade e seus diferentes enfoques no design ergonômico. In: . Ensaios em design: pesquisa e projetos. Bauru, SP: Canal 6, 2013. 